\title{
The Role of Temperature and Frequency on Fretting Wear of a Like-on-Like Stainless Steel Contact
}

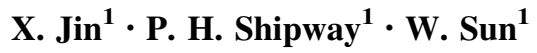

Received: 21 December 2016/ Accepted: 24 April 2017/Published online: 10 May 2017

(c) The Author(s) 2017. This article is an open access publication

\begin{abstract}
The influences of environmental temperature and fretting frequency on the mechanisms and rates of wear in a like-on-like 304 stainless steel contact were examined and mainly attributed to changes in the mechanical response of the bulk material and to changes in the behaviour of the oxide debris formed in the fretting process. At low temperatures, wear proceeds by continual oxide formation and egress from the contact, whilst at high temperatures, the rate of wear is much reduced, associated with the development of oxide formed into a protective bed within the contact. The temperature at which the change between these two behaviours took place was dependent upon the fretting frequency, with evidence that, at this transition temperature, changes in behaviour can occur as the fretting test proceeds under a fixed set of conditions. An interaction diagram has been developed which provides a coherent framework by which the complex effects of these two parameters can be rationalised in terms of widely accepted physical principles.
\end{abstract}

Keywords Fretting · Wear · Debris · Oxide ·

Yield strength

\section{Introduction}

Fretting between two bodies in contact typically results in damage in the form of either wear and/or fatigue [1]. It is known that rates and mechanisms of damage in fretting

X. Jin

jxjinxiaozhe@gmail.com

1 Faculty of Engineering, University of Nottingham, Nottingham, UK depend upon (amongst other things) both temperature and fretting frequency, and in recent work by the current authors, it was argued that these two do not act independently of each other [2]. The temperature affects the progress of fretting via: (1) the mechanical properties of the bodies undergoing fretting; (2) the rate of oxide formation on the fretting surfaces; (3) changes to the way that oxide particles thus formed either are retained in the contact (and potentially develop into a glaze) or are expelled from the contact $[3,4]$. The fretting frequency can also affect these three influences as a result of: (1) temperature changes in the region of the contact due to the variation of the friction power dissipation; (2) changes in the time between interactions of an asperity in the contact (which will influence the oxidation of the nascent metal which takes place); (3) changes in the motion of debris particles and thus their retention in (or egress from) the contact $[2,5]$. Details of these three primary mechanisms of influence will now be addressed.

The yield stress of a metal generally falls as the temperature is increased [6], and therefore, it is expected that fretting tests conducted at a higher environmental temperature will exhibit more significant plastic deformation. It was suggested by Kapoor [7] that plasticity by ratcheting can result in crack formation parallel to the surface leading to delamination. Moreover, Fouvry et al. [8] also argued that global surface shear plasticity can lead to high fretting wear rate.

Early work by Hurricks [9] classified the mechanisms of fretting wear into three stages, as follows:

1. Initial stage: direct metal-metal contact on the opposing surfaces leads to material adhesion and transfer between the surfaces;

2. Intermediate stage: oxide debris begins to be generated. It can either cause abrasion of the fretting bodies 
or begins to develop into a debris bed within the contact which will be constantly broken down and reformed;

3. Steady-state stage: a stable debris bed develops in the contact which acts as a third body solid lubricant between the fretting surfaces.

Previous studies [10-13] indicate that the presence of the oxide debris in the fretting contact can significantly influence the wear behaviour, with Godet [10] proposing the concept of the debris acting as the third body between the wearing surfaces which prevents direct contact between the primary surfaces. Iwabuchi et al. [14] studied the role of the debris by artificially supplying oxide particles into the contact (as opposed to the oxides being formed by the wear process itself) and concluded that the formation of a stable and compacted oxide layer will result in a reduction in wear, but if such a layer does not develop, the wear rate will be increased by the oxide particles acting as an abrasive. In further experiments to understand the role of the oxide in fretting, Colombie et al. [12] performed tests which were periodically interrupted to allow removal of the debris from the contact; these tests provided further evidence regarding the significance of the debris bed in determining fretting behaviour.

Temperature may have a significant influence on the way that the debris bed builds up within the fretting contact as follows:

1. The rate of oxide formation: in general, the oxidation rate of metals increases rapidly with temperature, and this will be as relevant in fretting as it is in normal thermal oxidation;

2. The nature of the oxide: it is well known that in steels, the dominant thermal oxidation product is dependent upon the temperature at which the oxidation occurs. In this regard, Hurricks [15, 16] argued that the oxide debris layer formed in fretting would contain more $\mathrm{Fe}_{3} \mathrm{O}_{4}$ rather than $\alpha-\mathrm{Fe}_{2} \mathrm{O}_{3}$ under high temperature. Moreover, Kayaba and Iwabuchi [17] suggested that the wear rate depended upon the nature of the oxide layer, with wear rates falling as the fraction of $\mathrm{Fe}_{3} \mathrm{O}_{4}$ increased;

3. The retention of oxide debris in the fretting contact and the development of a stable debris bed: it has been argued that as the temperature rises, there is an increase in the free energy of the debris particles which are forming in the fretting contact which encourages their mutual adhesion and retention within the contact and thus their formation into a stable and compacted debris bed [18]. In addition, it has been argued that $\mathrm{Fe}_{3} \mathrm{O}_{4}$ adheres more strongly than $\mathrm{Fe}_{2} \mathrm{O}_{3}$ onto the wearing surfaces which again encourages the formation of a stable debris bed [19, 20].
After the formation of a compacted debris layer (steadystate stage), further consolidation of this layer may occur due to sintering, resulting in the formation of a protective glaze layer. The glaze is a smoothly burnished outer region of the debris bed itself [21]; it has been argued that its formation is directly related to the completion of the debris particle sintering process $[13,22]$. Despite sintering being a process which is normally considered to be significant when the homologous temperature is above 0.5, [23], Pearson et al. [24] argued that debris sintering occurred at temperatures as low as $85^{\circ} \mathrm{C}$ in fretting of a high-strength steel.

It is clear that oxide debris plays a major role in determining behaviour in the intermediate and steady-state stages of fretting. Moreover, it can be seen that both the temperature and the fretting frequency have a significant influence on fretting wear via changes in the oxidation rate and subsequent behaviour of the oxide debris within the contact. In this work, both environmental temperature and fretting frequency (since fretting frequency also exerts a strong influence on the contact temperature [25]) were varied to study their effects on fretting behaviour of a stainless steel. Extending our previous work [2], tests of different (and extended) durations were conducted in order that the evolution of damage can be understood.

\section{Experimental Procedure}

The experimental methods and materials used in this work have been described in detail in previous work [2] but will be outlined again here for completeness.

\subsection{Specimen, Test Procedures and Conditions}

Fretting experiments were conducted on 304 stainless steel specimens; the chemical composition of which is presented in Table 1. Specimens were assembled in a cylinder-on-flat arrangement (Fig. 1) with a normal load, $P$, being applied via a deadweight (Fig. 2). An electromagnetic vibrator (EMV) was used to develop the fretting motion perpendicular to the axis of the cylindrical specimen (Fig. 1). The far-field displacement of the upper specimen mounting block (USMB) was measured through a capacitance

Table 1 Chemical composition of 304 stainless steel (wt \%) measured by atomic emission spectroscopy (Foundry Master, Oxford Instruments, UK)

\begin{tabular}{llllllll}
\hline $\mathrm{C}$ & $\mathrm{Si}$ & $\mathrm{Mn}$ & $\mathrm{P}$ & $\mathrm{S}$ & $\mathrm{Cr}$ & $\mathrm{Mo}$ & $\mathrm{Ni}$ \\
0.027 & 0.816 & 1.79 & 0.013 & 0.025 & 17.2 & 0.303 & 10.3 \\
$\mathrm{Al}$ & $\mathrm{Co}$ & $\mathrm{Cu}$ & $\mathrm{Nb}$ & $\mathrm{Ti}$ & $\mathrm{V}$ & $\mathrm{W}$ & $\mathrm{Fe}$ \\
0.003 & 0.083 & 0.347 & 0.012 & 0.008 & 0.044 & 0.035 & Remainder \\
\hline
\end{tabular}




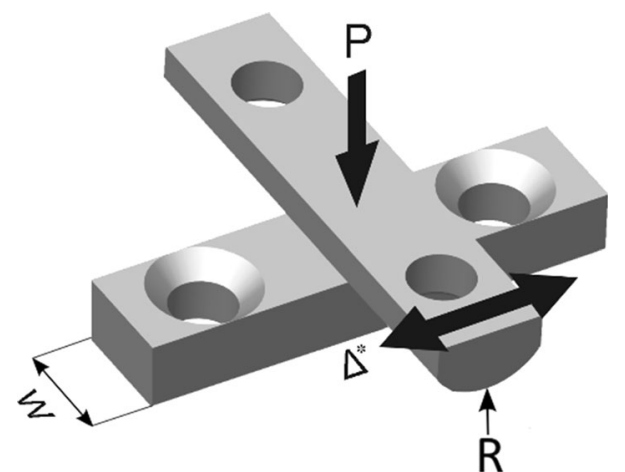

Fig. 1 Cylinder-on-flat specimen arrangement in fretting test: $W=10 \mathrm{~mm}, R=6 \mathrm{~mm}, P=450 \mathrm{~N}$, and $\Delta^{*}=50 \mu \mathrm{m} \mathrm{[26]}$

displacement sensor, with this position data being used to control the motion of the USMB. A piezoelectric load cell was used to measure the tangential force $(Q)$ across the contact. Both the USMB displacement and the tangential force were recorded continuously at the rate of 200 samples per fretting cycle and were plotted against each other as fretting loops. A schematic fretting loop is presented in Fig. 3. The slip amplitude $\left(\delta^{*}\right)$ refers to slip that occurs in the contact and is not the same as the applied displacement amplitude $\left(\Delta^{*}\right)$ which is the parameter which is used to control the motion of the USMB. The slip amplitude is smaller than the displacement amplitude due to contact and rig compliances. The combined system stiffness, $S$, is defined as the gradient of the steep side of the fretting loop (see Fig. 3) [27, 28]; in this work, the system stiffness, $S$, was estimated to lie in the range of $30-37 \mathrm{MN} \mathrm{m}^{-1}$. The energy dissipated per fretting cycle $\left(E_{\mathrm{d}}\right)$ can be measured from a fretting loop and the energy-based coefficient of friction $\left(\mu_{\mathrm{E}}\right)$ derived from this as follows:

$\mu_{\mathrm{E}}=\frac{E_{\mathrm{d}}}{4 P \delta^{*}}$

Fig. 2 Main components of

fretting apparatus [26]

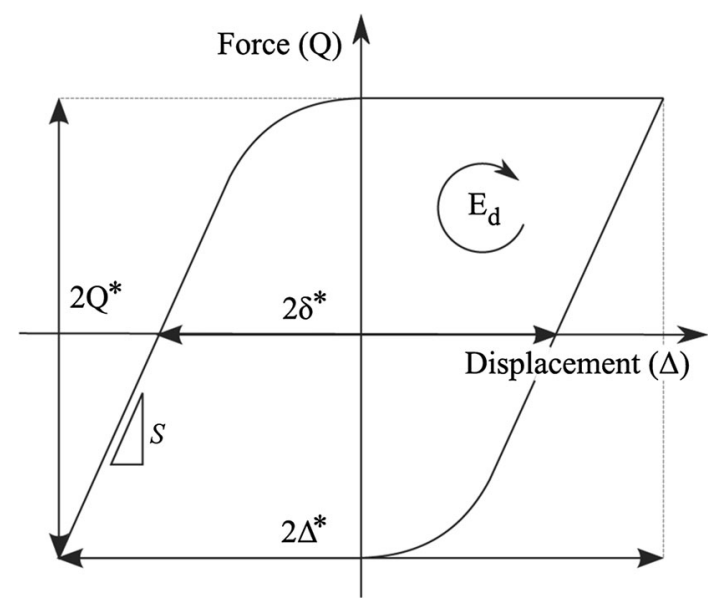

Fig. 3 Schematic fretting loop

Electrical heaters in the system allowed independent control of the temperature of each specimen which was measured and controlled via open wire thermocouples which were welded onto the top surface of each specimen. To minimise the influence of the temperature rise induced by the frictional power dissipation on the temperature measurements of the thermocouples, the thermocouples have been welded at the end of each specimen which is approximately $20 \mathrm{~mm}$ away from the fretting contact itself. In this programme of work, both specimens were maintained at the same temperature. As a modification to the test set-up employed in previous work [2], a layer of thermal insulation was used to cover the whole test area to limit heat flow and reduce thermal gradients.

Tests were performed with temperatures between ambient and $275^{\circ} \mathrm{C}$ at two fretting frequencies (20 and $200 \mathrm{~Hz}$ ). Test conditions are summarised in Table 2.

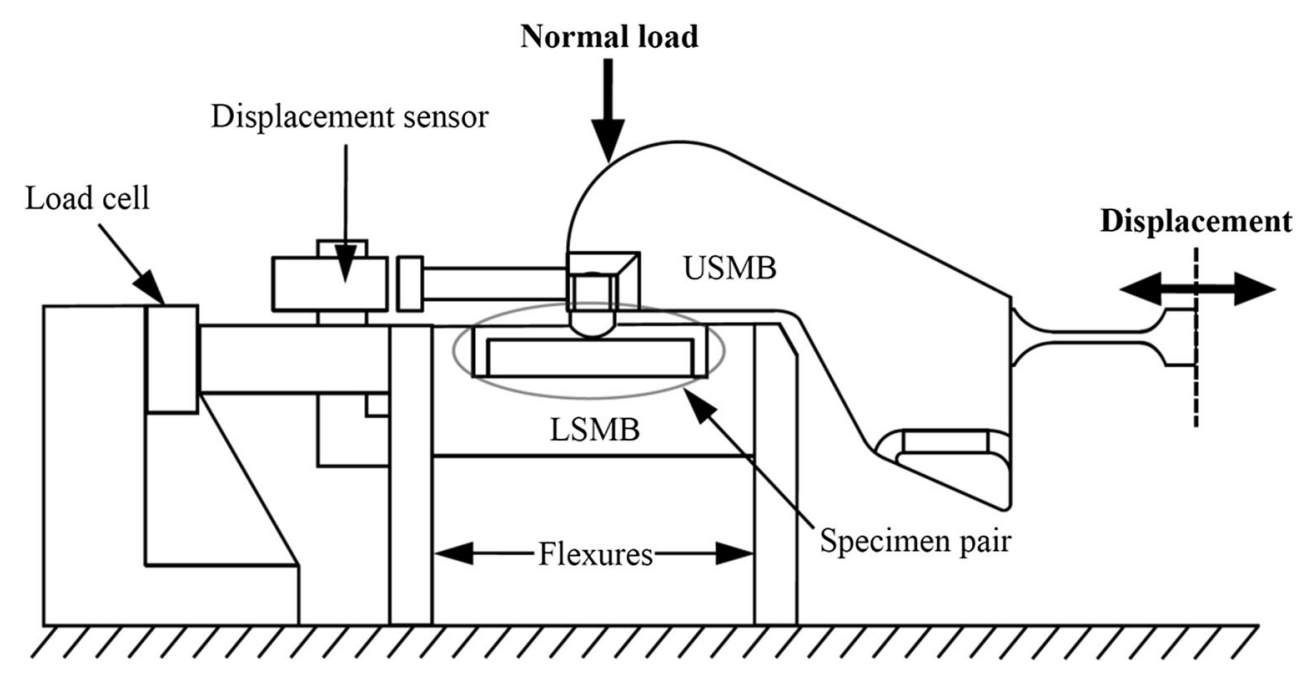


Table 2 Fretting test conditions

\begin{tabular}{lll}
\hline Normal load & $P(\mathrm{~N})$ & 450 \\
Applied displacement & $\Delta^{*}(\mu \mathrm{m})$ & 50 \\
Duration & $N$ (thousand cycles) & $10,30,100,500$ \\
Frequency & $f(\mathrm{~Hz})$ & 20,200 \\
Temperature & $T\left({ }^{\circ} \mathrm{C}\right)$ & Amb to 275 \\
\hline
\end{tabular}

\subsection{Estimation of Wear Volume and Wear Rate}

Following a fretting test, both specimens were lightly swabbed with industrial methylated spirit to remove loose debris. The topography of the wear scars on both the flat and cylindrical specimens was evaluated with a Bruker contour GT-I interferometer. The profilometric data relating to the surface outside the wear scar were extrapolated to create a reference surface (representing the surface profile of before wear occurred). The volume below each reference surface was regarded as the wear volume ( $V_{\text {Flat }}^{-}$ and $V_{\mathrm{Cyl}}^{-}$for the flat and cylindrical specimens, respectively) and the volume of material above these surfaces was regarded as transferred volume $\left(V_{\text {Flat }}^{+}\right.$and $V_{\text {Cyl }}^{+}$for the flat and cylindrical specimens, respectively) (see Fig. 4). The total wear and transfer volumes for the couple $\left(V^{-}\right.$and $V^{+}$, respectively) are defined as the sum of the respective volumes for the flat and cylindrical specimens. A number of tests were repeated, and typically, the reproducibility in wear volumes was $\sim 5 \%$.

Scanning electron microscopy (SEM) using back-scattered electron (BSE) imaging was used to characterise the wear scars, in both plan and sectional views. The BSE images were used to identify the distribution of the lower contrast oxide debris within the wear scars. Energy-dispersive X-ray spectroscopy (EDX) in the SEM was also employed to identify the nature of various regions within the scars.

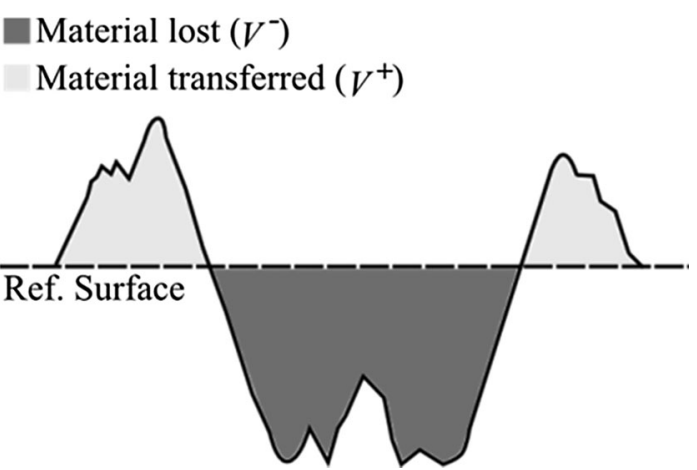

Fig. 4 Schematic diagram indicating the assessment of transfer and wear volume

\section{Experimental Results}

Tests with different number of cycles $(10,30,100,500 \mathrm{k}$ cycles) were performed at three temperatures (Amb, $125^{\circ} \mathrm{C}, 275^{\circ} \mathrm{C}$ ) for both frequencies to study the evolution of the wear behaviour. Figure 5 shows the development of the $\mu_{\mathrm{E}}$ through the tests. It can be seen that at both frequencies, $\mu_{\mathrm{E}}$ were highest at $125{ }^{\circ} \mathrm{C}$ and lowest at $275{ }^{\circ} \mathrm{C}$. At $20 \mathrm{~Hz}$, frequent fluctuation in $\mu_{\mathrm{E}}$ (of the order of $\sim 0.1$ ) was observed at room temperature, indicating the instability of the contact surfaces in this condition. At $275{ }^{\circ} \mathrm{C}$ for both fretting frequencies, the $\mu_{\mathrm{E}}$ dropped very quickly after $\sim 20,000-50,000$ cycles and became relatively stable after this, with a slight long-term reduction being observed. The $\mu_{\mathrm{E}}$ at $125{ }^{\circ} \mathrm{C}$ was in general high and relatively stable, although some fluctuations were observed in the first 200,000 cycles. The fluctuations observed were generally less significant at the higher fretting frequency.

Figure 6 shows the evolution of both the wear and transfer volumes up to half a million cycles. At room temperature, material transfer volumes are almost zero throughout the whole process for both frequencies. The wear volumes increase approximately linearly with the number of fretting cycles for both frequencies, with the wear volumes observed at $20 \mathrm{~Hz}$ being almost twice as large as those observed at $200 \mathrm{~Hz}$. At $275^{\circ} \mathrm{C}$, both wear and transfer volumes were very low at both frequencies and remain very close to each other across the range of test durations examined. At the lower frequency, the wear and transfer volumes slowly increased with increasing number of fretting cycles; however, at the higher fretting frequency, they remained almost constant with increasing numbers of fretting cycles (i.e. the instantaneous wear rate tended towards zero). It should be noted that at both frequencies, the transfer volumes are slightly higher than the wear volumes at this test temperature, which indicates that there is an increase in the total material volume after fretting (due to these oxides having a Pilling-Bedworth ratio significantly greater than unity).

There is clearly a transition between the behaviour at room temperature and the behaviour at $275^{\circ} \mathrm{C}$. At the intermediate temperature of $125^{\circ} \mathrm{C}$, the behaviour is significantly different at the two frequencies, indicating that the transition temperature is dependent upon frequency. At $200 \mathrm{~Hz}$, the behaviour at $125{ }^{\circ} \mathrm{C}$ is very similar to that observed at room temperature; in both cases, the wear volumes increased approximately linearly with the number of cycles (with very similar magnitudes), whilst the transfer volumes remained very low across the number of cycles. This indicates that at this frequency, the transition between low temperature and high temperature behaviour occurs somewhere between 125 and $275{ }^{\circ} \mathrm{C}$. However, at $20 \mathrm{~Hz}$, 
(a)

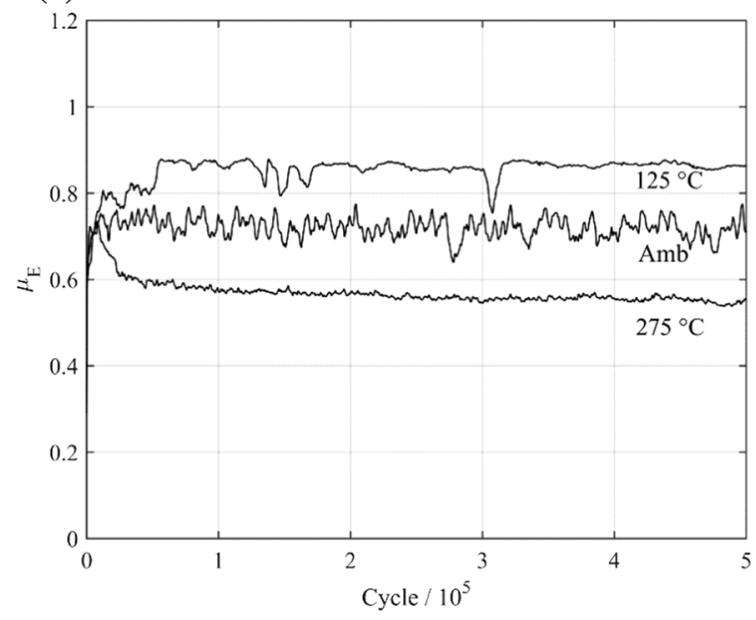

(b)

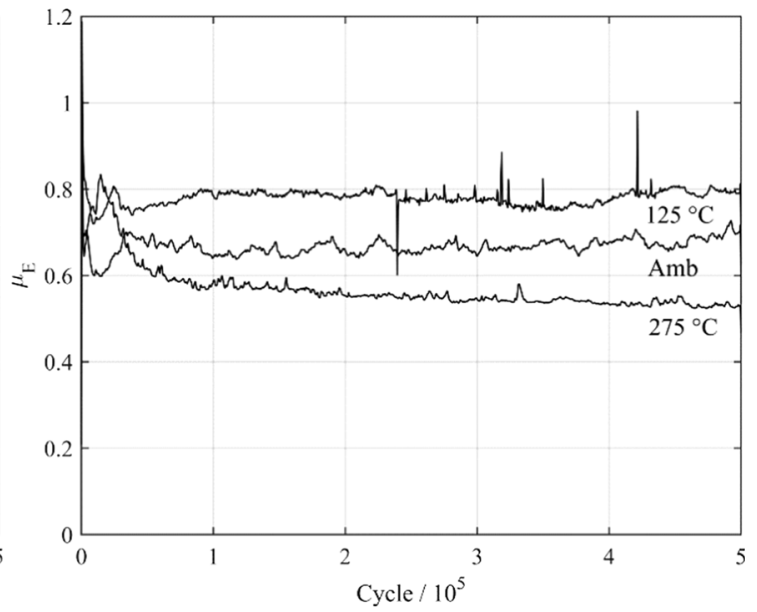

Fig. 5 Energy-based coefficient of friction $\left(\mu_{\mathrm{E}}\right)$ as a function of number of cycles under three test temperatures $\left(\mathrm{Amb}, 125{ }^{\circ} \mathrm{C}, 275^{\circ} \mathrm{C}\right)$ at fretting frequencies of (a) $20 \mathrm{~Hz}$ and (b) $200 \mathrm{~Hz}$

very different behaviour is observed at $125{ }^{\circ} \mathrm{C}$ compared to that at room temperature. Initially, at $125^{\circ} \mathrm{C}$, both the wear rate and transfer rate were high, and almost equal to each other (indicating limited material loss from the contact, and instead, material redistribution). However, by the point that 100,000 cycles have been reached, the wear volume is significantly larger than the transfer volume, but both of these were very large compared to their respective volumes observed in any of the other tests at this number cycles, which is one of most distinguishing features of this test. However, uniquely within this test, it is clear that a significant change in the wear behaviour has occurred at around 100,000 cycles; prior to 100,000 cycles being reached, wear and transfer volumes increased rapidly, but after 100,000 cycles, the increase in wear volume was very slow, exhibiting a rate similar to that observed at the higher temperature of $275^{\circ} \mathrm{C}$. The transfer volume at 100,000 cycles is actually larger than that which is observed in the tests following 500,000 cycles, but it should be noted that this does not necessarily imply a reduction (due to repeatability and confidence issues) but does imply that again the rate of change in the transfer volume is very low in this region.

In light of the significant change in wear rate at 100,000 cycles in Fig. 6c, further tests were conducted for 100,000 cycles with a range of temperatures bracketing that at which the transition was observed at $20 \mathrm{~Hz}(100,150$ and $200{ }^{\circ} \mathrm{C}$ ) under both low and high frequencies. Figure 7 shows the total wear volume $\left(V^{-}\right)$and total material transfer volume $\left(V^{+}\right)$as a function of test temperature at 100,000 cycles at fretting frequencies of both 20 and $200 \mathrm{~Hz}$. At this number of cycles, it can be seen that the fretting wear behaviour is strongly dependent on both the test temperature and the fretting frequency (although it is recognised that these observations are only relevant for this selected test duration). At $20 \mathrm{~Hz}$, almost no material transfer occurs (but only wear) when fretting is conducted at room temperature. With increasing temperature, both wear and transfer volumes increase, with the highest values recorded being from the tests conducted at $125^{\circ} \mathrm{C}$. Both volumes then decrease as the test temperature is further increased with low wear and transfer volumes being observed at the highest temperature of $275^{\circ} \mathrm{C}$; moreover, the wear and transfer volumes are very similar at this test temperature. It should be noted that at $125^{\circ} \mathrm{C}$, the wear volume is extremely high compared to that observed at the other test temperatures (almost twice as that observed at room temperature and around six times as that observed at $275^{\circ} \mathrm{C}$ ), although it is noted that the transfer volume also exhibits its highest value at the same temperature. In light of the changes observed at $125{ }^{\circ} \mathrm{C}$ for testing conducted at $20 \mathrm{~Hz}$, this frequency-dependent temperature is referred to as a critical temperature. For the $200 \mathrm{~Hz}$ case, in general, both the wear and transfer volumes are either comparable to or lower than those observed in the tests conducted at the lower frequency. No critical temperature with very high wear and transfer volumes is observed. However, the same trend of an increase in wear volume followed by a decrease for both frequencies is evident. It should be noted that at both frequencies, the transfer volume is higher than the wear volume at $275^{\circ} \mathrm{C}$.

Figure 8 shows the average surface profiles across the wear scars on the flat specimens at three temperatures [namely the lowest (RT) and highest $\left(275^{\circ} \mathrm{C}\right)$ temperatures examined, along with the critical temperature identified for the $20-\mathrm{Hz}$ case $\left.\left(125^{\circ} \mathrm{C}\right)\right]$ for both fretting frequencies at 100,000 cycles. At the lower frequency (Fig. 8a), only material removal has occurred at room temperature. At test temperature of $125^{\circ} \mathrm{C}$, the scar is much wider and deeper, 
(a)

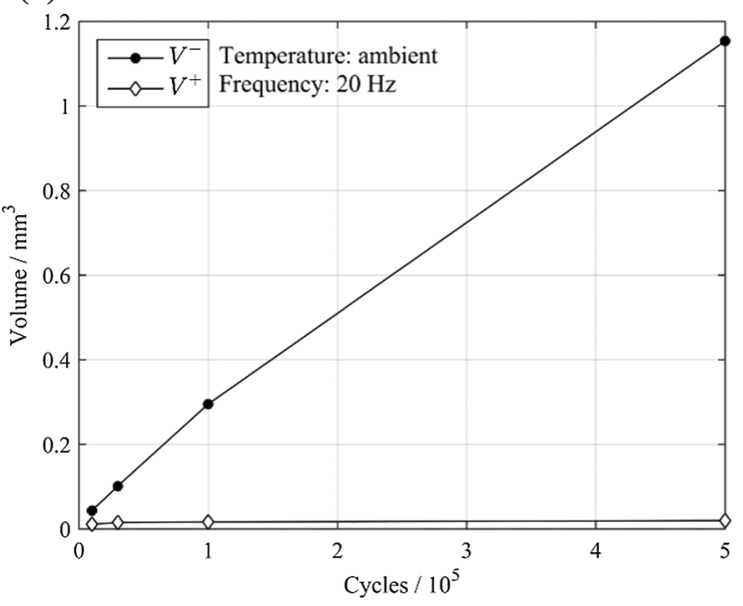

(c)

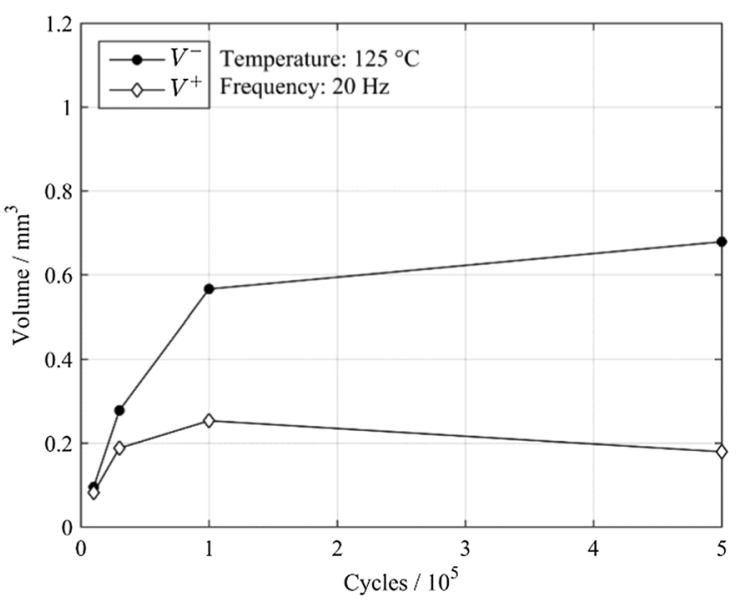

(e)

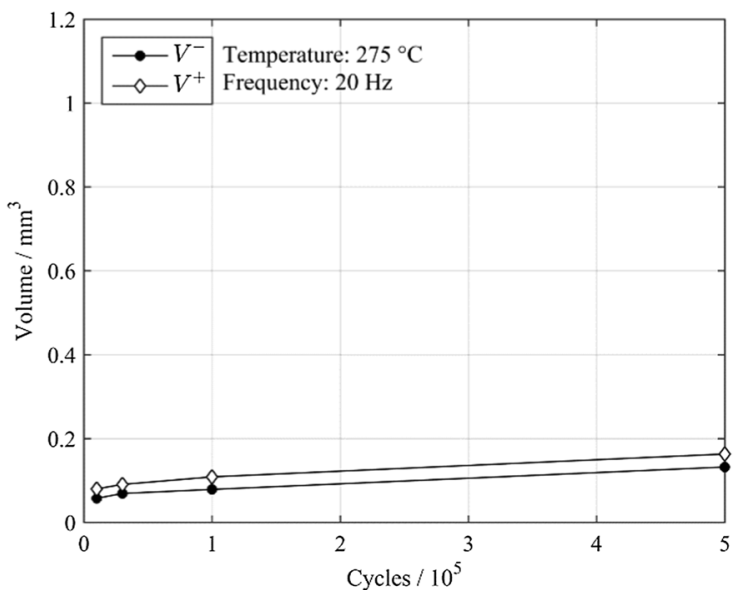

(b)

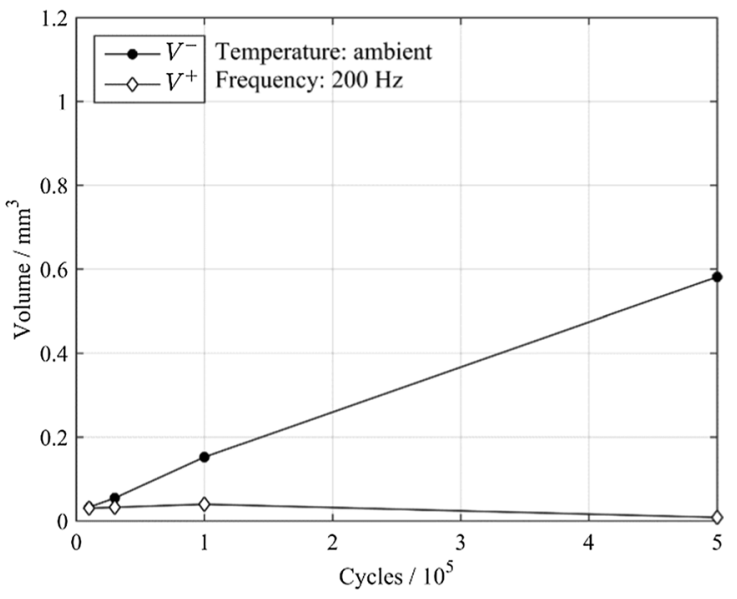

(d)

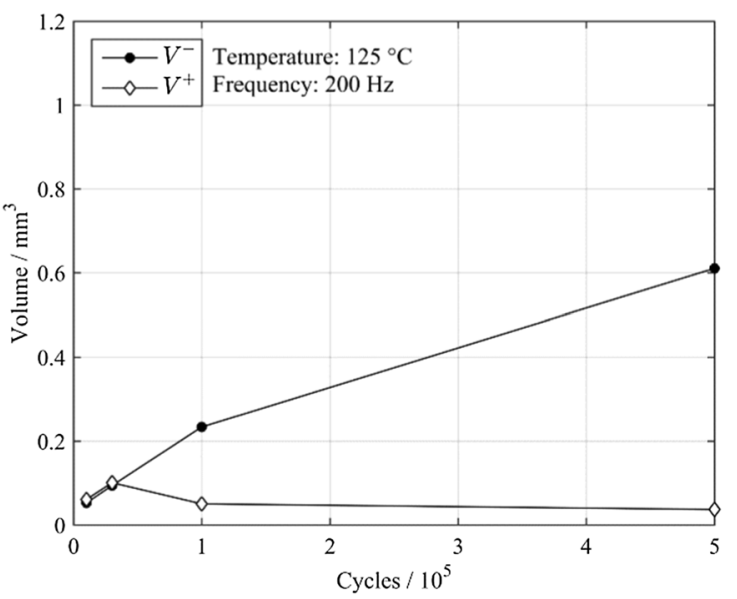

(f)

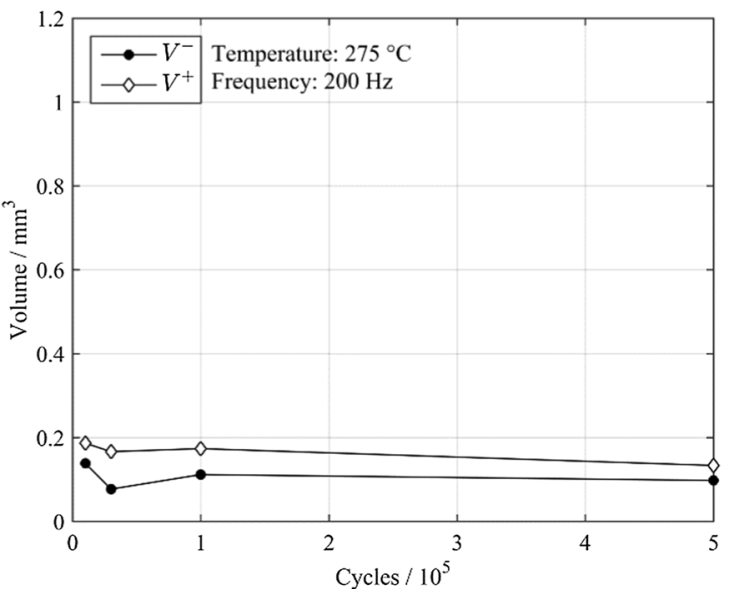

Fig. 6 Wear volume $\left(V^{-}\right)$and transfer volume $\left(V^{+}\right)$as a function number of cycles under three test temperatures (ambient, $\left.125{ }^{\circ} \mathrm{C}, 275{ }^{\circ} \mathrm{C}\right)$ and two fretting frequencies $(20,200 \mathrm{~Hz})$

with significant material build-up occurring at both sides of the scar. With a further increase in temperature to $275^{\circ} \mathrm{C}$, the scar is much smaller again, but unlike the profile at room temperature, there is still significant material build-up at the scar edges. The profiles from scars generated by fretting at the higher frequency (Fig. 8b) have both similarities and differences in comparison with those from tests conducted at the lower frequency. At room temperature, obvious material 

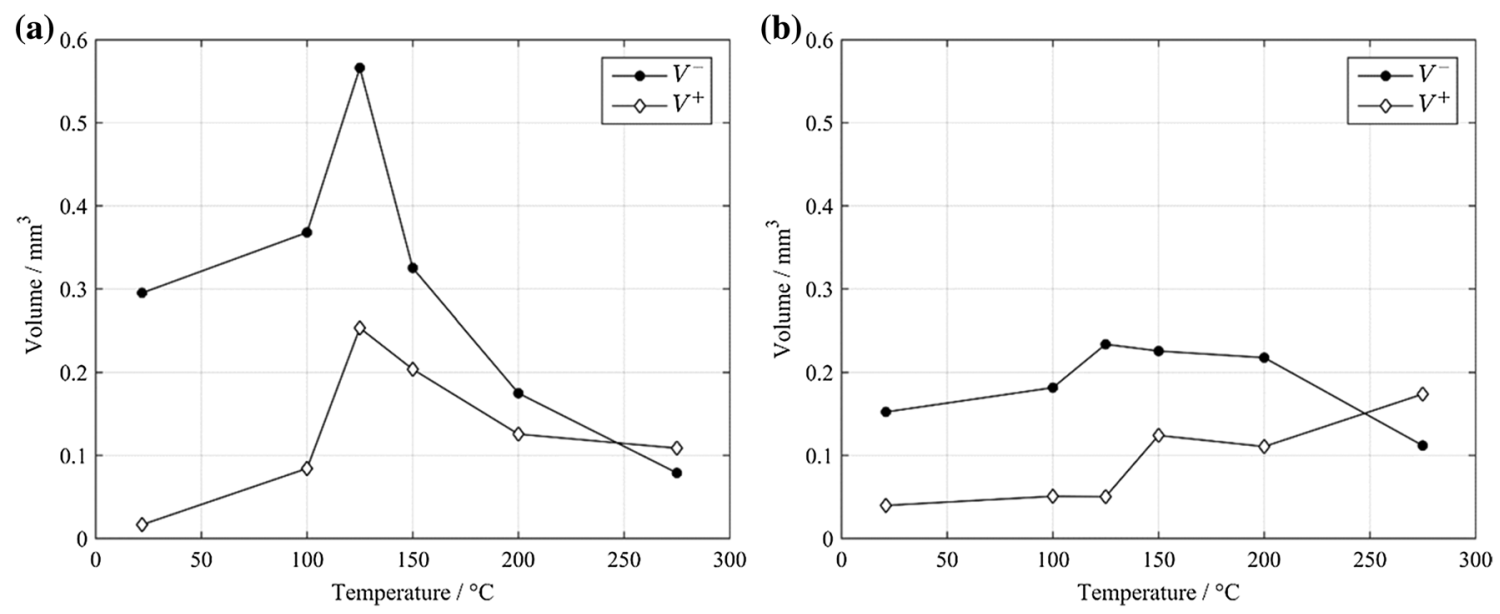

Fig. 7 Wear volume $\left(V^{-}\right)$and transfer volume $\left(V^{+}\right)$as a function of test temperature at 100,000 cycles at fretting frequencies (a) $20 \mathrm{~Hz}$ and (b) $200 \mathrm{~Hz}$

(a)

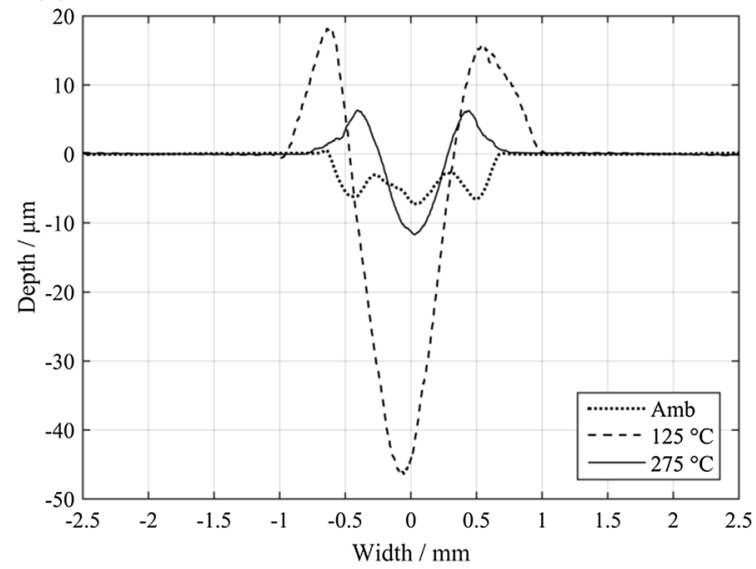

(b)

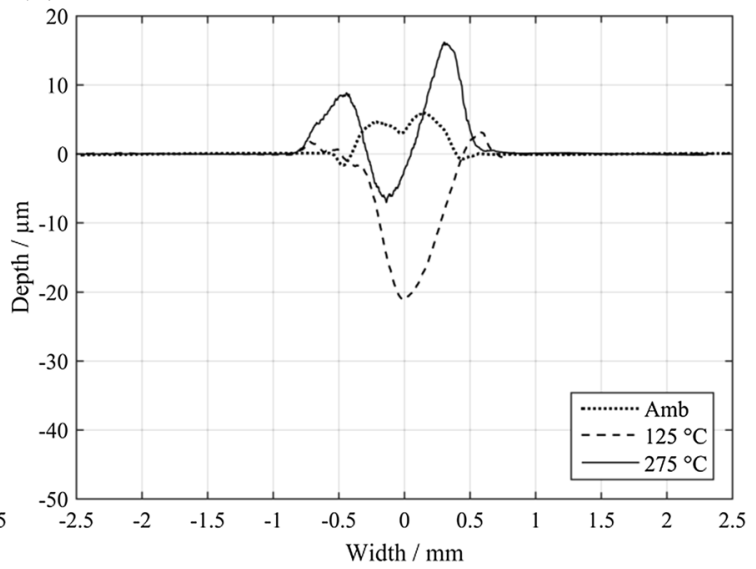

Fig. 8 Average surface profiles across the wear scars on the flat specimens as a function of test temperatures at 100,000 cycles at fretting frequencies of (a) $20 \mathrm{~Hz}$ and (b) $200 \mathrm{~Hz}$

build-up on the flat specimen can be observed across the scar width. As this build-up is not compensated for elsewhere in the scar, this indicates that in this case, a fraction of the material lost from the cylindrical specimen (see $V^{-}$at this number of cycles in Fig. 6b) has been transferred to the flat specimen. Similar to the lower frequency, the scar gets much deeper at test temperature of $125{ }^{\circ} \mathrm{C}$, but it is much less deep than the scar generated at $20 \mathrm{~Hz}$; also, there is no substantial build-up of material at the edges of the scar as was seen for the lower frequency test. The scar profiles following testing at $275{ }^{\circ} \mathrm{C}$ are similar in size and shape at both the high and low frequencies.

Figure 9 shows the BSE SEM images of the plan view of the wear scars on the flat specimens following fretting for increasing numbers of cycles at $20 \mathrm{~Hz}$ at the three selected temperatures. At room temperature, the scars keep growing in width with the increase in the number of fretting cycles. All the scars are evenly covered with oxide- based debris, but the debris layer exhibits a lighter grey contrast than the debris layers generated at the other temperatures, indicating that it has a more metallic character (or is significantly thinner). Regions with clear metallic features (much brighter contrast regions) can be observed spread across the scars, even in the scar following fretting for 500,000 cycles; this indicates that the oxide layer has been lost from these areas. At $125{ }^{\circ} \mathrm{C}$, even following only 10,000 cycles of fretting, localised regions of severe damage and debris build-up can be seen. This variation in the degree of damage across the width of the SEM image (about $4 \mathrm{~mm}$ in width) persists in the wear scar following fretting for 100,000 cycles, but has largely been eliminated following fretting for 500,000 cycles. The three-dimensional surface profiles of the flat specimens with different numbers of cycles exhibit this localisation of damage (Fig. 10), indicating that the regions where damage appears to be more prevalent are in fact very deep in the middle of 

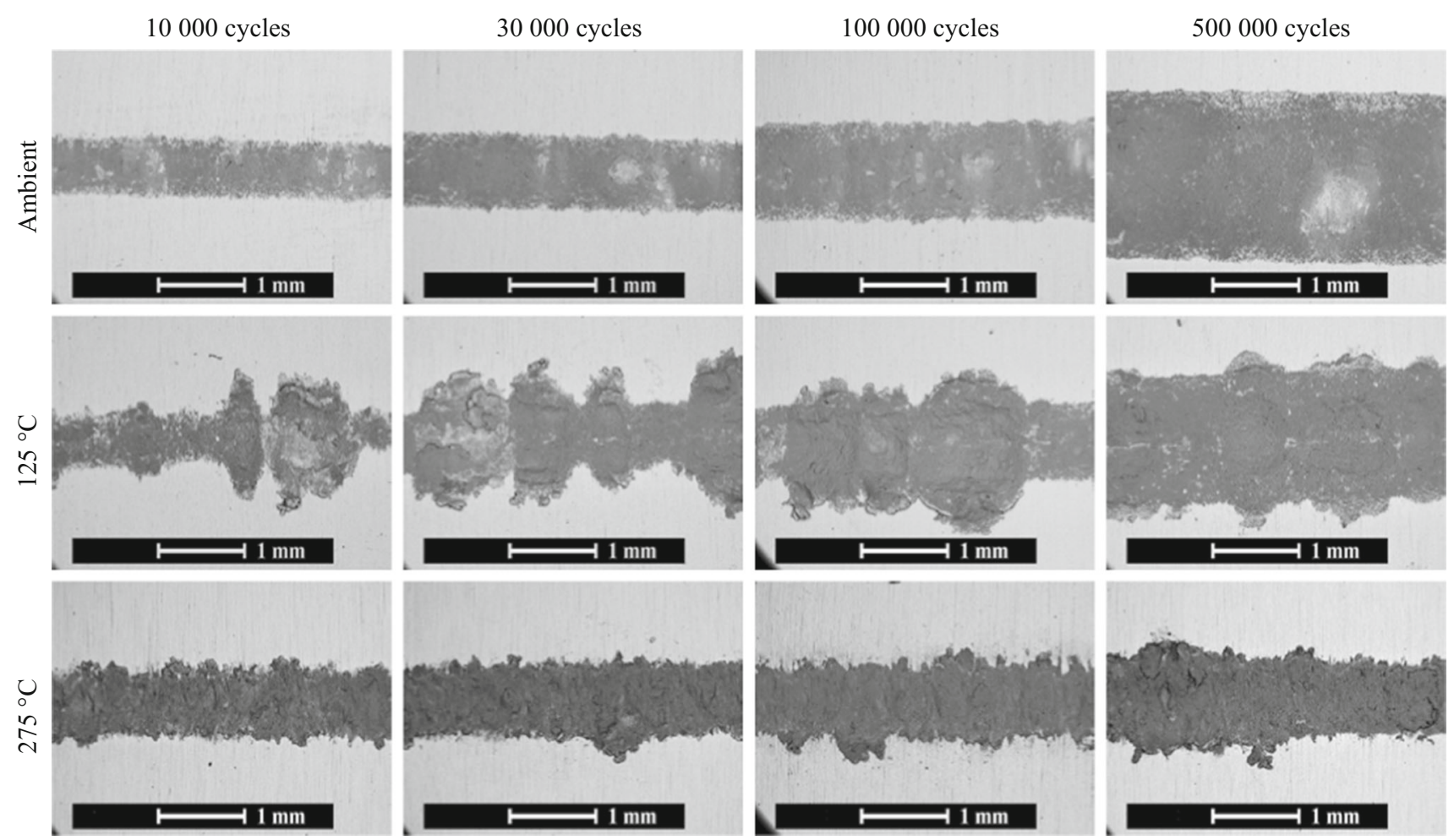

Fig. 9 Back-scattered electron SEM plan-view micrographs of wear scars on the flat specimens as a function of temperature and number of cycles at fretting frequency of $20 \mathrm{~Hz}$

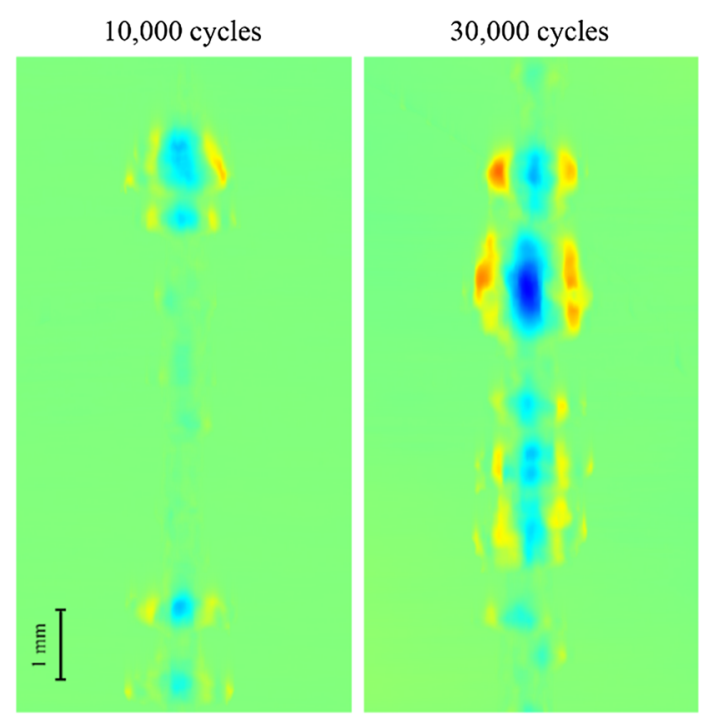

Fig. 10 Topography of the surface of the flat specimen with the increase in fretting cycles with a test temperature of $125^{\circ} \mathrm{C}$ and a fretting frequency of $20 \mathrm{~Hz}$. The height information is indicated by

the scar and have associated significant build-up of material (oxide-based debris or displaced substrate material) outside the main contact area. This localisation of damage along with regions with clear metallic character within the scar exists at the lower number of cycles, but have been broadly eliminated (being replaced by an oxide-based
100,000 cycles

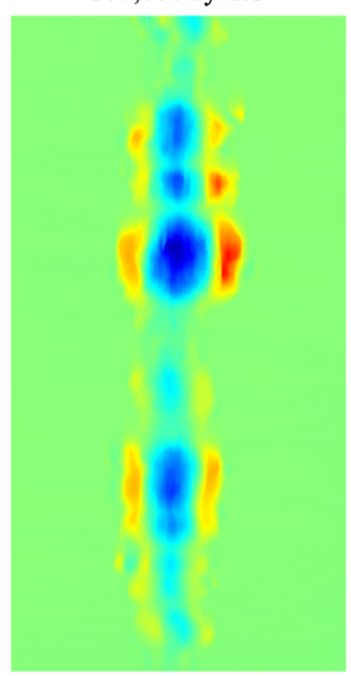

500,000 cycles

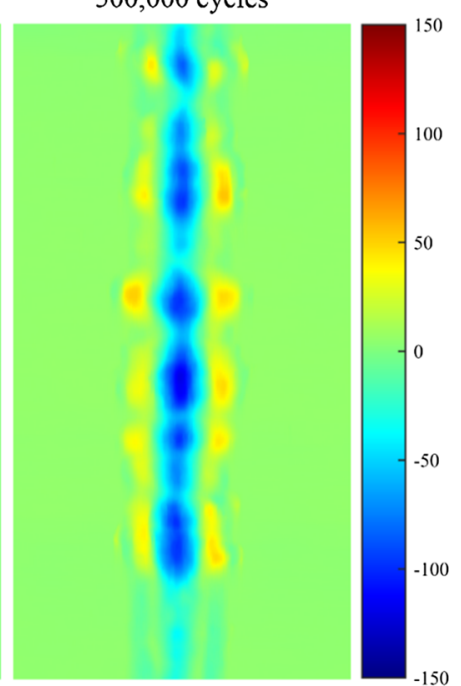

colour, with the colour scale marker being calibrated in micrometres (Color figure online)

debris layer with almost complete coverage) following fretting for 500,000 cycles. At $275^{\circ} \mathrm{C}$, the scar is covered with a compacted and complete oxide-based debris layer even following fretting for only 10,000 cycles (with very little evidence of any regions with strongly metallic character). There is only very slight growth in the width of the 
wear scar as the number of fretting cycles increases even up to 500,000 cycles; in addition, the morphology of the wear scar surface appears to be almost independent of the number of cycles. It should be noted that the wear damage following testing at both room temperature and $275^{\circ} \mathrm{C}$ is uniformly distributed along the contact line; therefore, only the three-dimensional surface profiles of the tests under $125{ }^{\circ} \mathrm{C}$ (which exhibit localisation of damage) have been presented.

To study the structure of the oxide layers on the wear scars, the flat specimens from the tests fretted for 100,000 cycles have been sectioned and examined via BSE SEM imaging. The top row in Fig. 11 shows overviews of the whole scars at the three temperatures, with the images below providing higher magnification images of certain regions within the scars. At room temperature, there is partial coverage of the wear scar surface with oxide debris layers. In these regions, the oxide layer is thick (about $20 \mu \mathrm{m}$ ), with evidence that shear damage occurs within the oxide debris layer itself (as indicated by the cross-hatch pattern of damage); similar patterns of oxide shear in fretting have been reported elsewhere [29]. At $125^{\circ} \mathrm{C}$, significant material build-up towards the edges of the scar is observed; this material is metallic substrate material (as opposed to oxide debris) which has been plastically deformed and pushed above the original surface. Towards the edges of the main scars, a thick (about $30 \mu \mathrm{m}$ ) and compacted oxide debris layer is partly formed on the worn surface. Large $(\sim 1 \mu \mathrm{m})$ metallic particles (very bright compared to the surrounding oxide-based debris) can be observed inside the layer. The oxide in the middle of the scar is much thinner, but again exhibits the presence of metallic particles within the debris. At $275^{\circ} \mathrm{C}$, the whole scar is covered with thin $(\sim 5 \mu \mathrm{m})$ but highly compacted oxide layer. EDX analysis has been performed on the oxide layers for all test temperatures. The results qualitatively indicate that the debris layers have a higher oxide content at 125 and $275{ }^{\circ} \mathrm{C}$.

Given that there appears to be a change in damage mechanism in the samples fretted at $125{ }^{\circ} \mathrm{C}$ and $20 \mathrm{~Hz}$ between 100,000 cycles and 500,000 cycles, a further cross section was examined following fretting for 500,000 cycles under these conditions, with the SEM images being shown in Fig. 12. Following 500,000 cycles, a thick (about
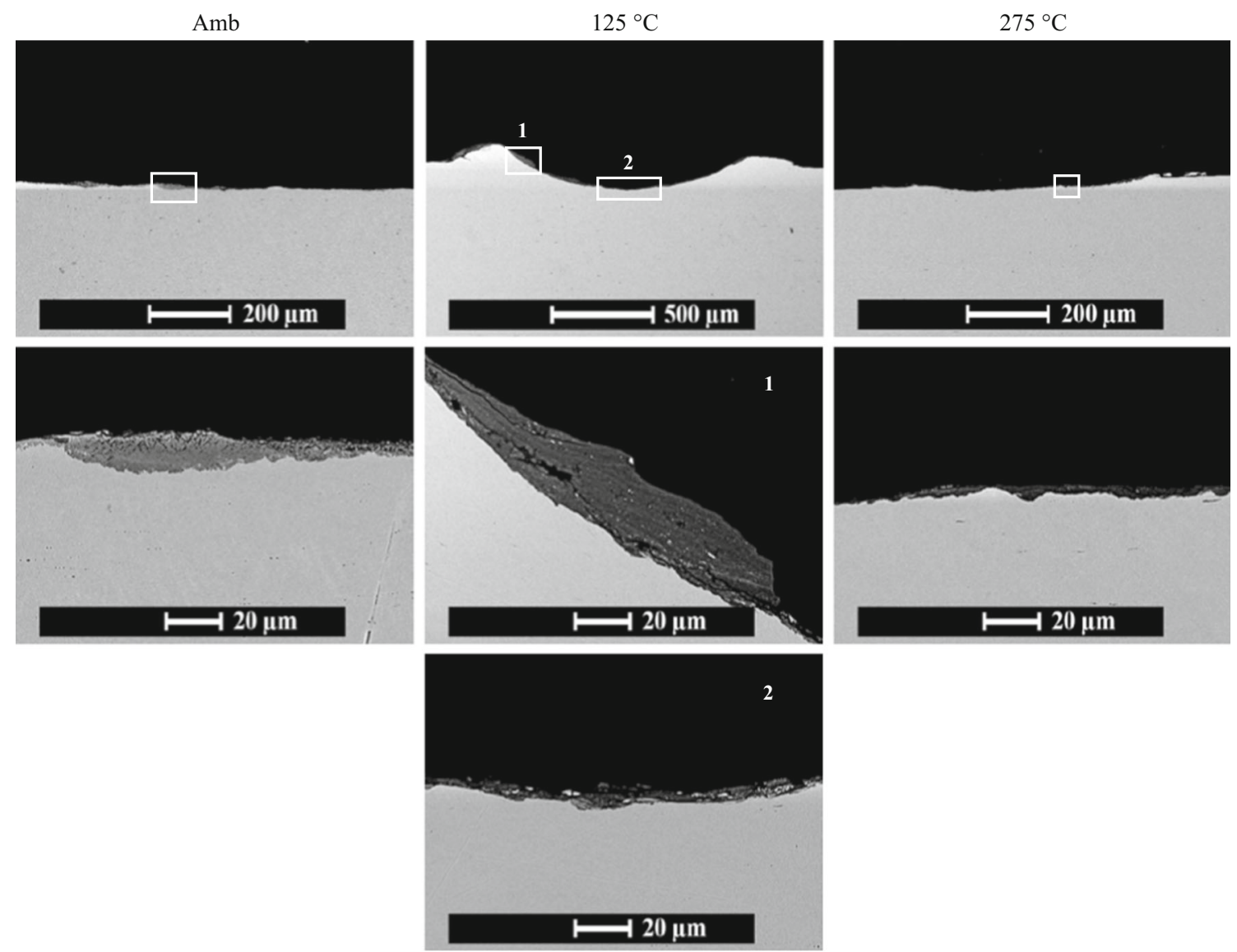

Fig. 11 Back-scattered electron SEM cross-sectional micrographs of wear scars on the flat specimens with different temperatures (ambient, $125^{\circ} \mathrm{C}, 275^{\circ} \mathrm{C}$ ) at 100,000 cycles with fretting frequency of $20 \mathrm{~Hz}$ 

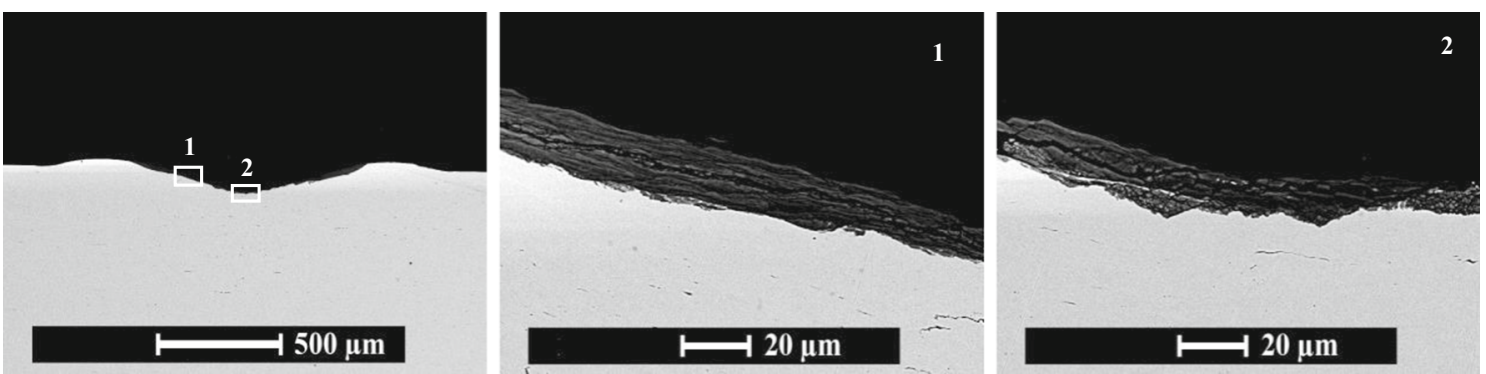

Fig. 12 Back-scattered electron SEM cross-sectional micrographs of wear scars on the flat specimens with test temperature of $125{ }^{\circ} \mathrm{C}$ at 500,000 cycles with fretting frequency of $20 \mathrm{~Hz}$

$20 \mu \mathrm{m})$ oxide-based debris layer has been observed to cover almost all of the scar; whilst exhibiting fairly full coverage, it is not as compact as the debris observed following fretting at $275^{\circ} \mathrm{C}$.

Figure 13 shows the BSE SEM images of the plan view of the wear scars on the flat specimens following fretting for increasing numbers of cycles at $200 \mathrm{~Hz}$ at the three selected temperatures. After 10,000 cycles, clear metallic surfaces are exposed in the middle of the scar at all three test temperatures. At room temperature, only small part of the scar at the edges is covered with oxide; this increases at higher test temperatures, but the whole scar is not covered, even at $275{ }^{\circ} \mathrm{C}$. At room temperature, as the number of fretting cycles increases, the wear scar starts to become evenly covered with oxide-based debris but clear metallic features can still be observed; there is a similarity between the scars generated at 20 and $200 \mathrm{~Hz}$ for the larger numbers of cycles. At $125{ }^{\circ} \mathrm{C}$, with the development of the wear scar, localised regions of severe damage can again be seen, but these appear to be less significant than those observed in the tests at this temperature at $20 \mathrm{~Hz}$. The majority of the scar is covered with oxide-based debris after 30,000 cycles, but clear metallic features can also be observed. The oxide layer developed at this test appears to be less dense and compact than the one developed at $125{ }^{\circ} \mathrm{C}$ under $20 \mathrm{~Hz}$. At $275{ }^{\circ} \mathrm{C}$, the fretting scar is almost completely covered with a compacted oxide-based debris layer after 30,000 cycles; there is a little change in the width and nature of the wear scar following 30,000 cycles, which is similar to the behaviour observed at same temperature under fretting at $20 \mathrm{~Hz}$.
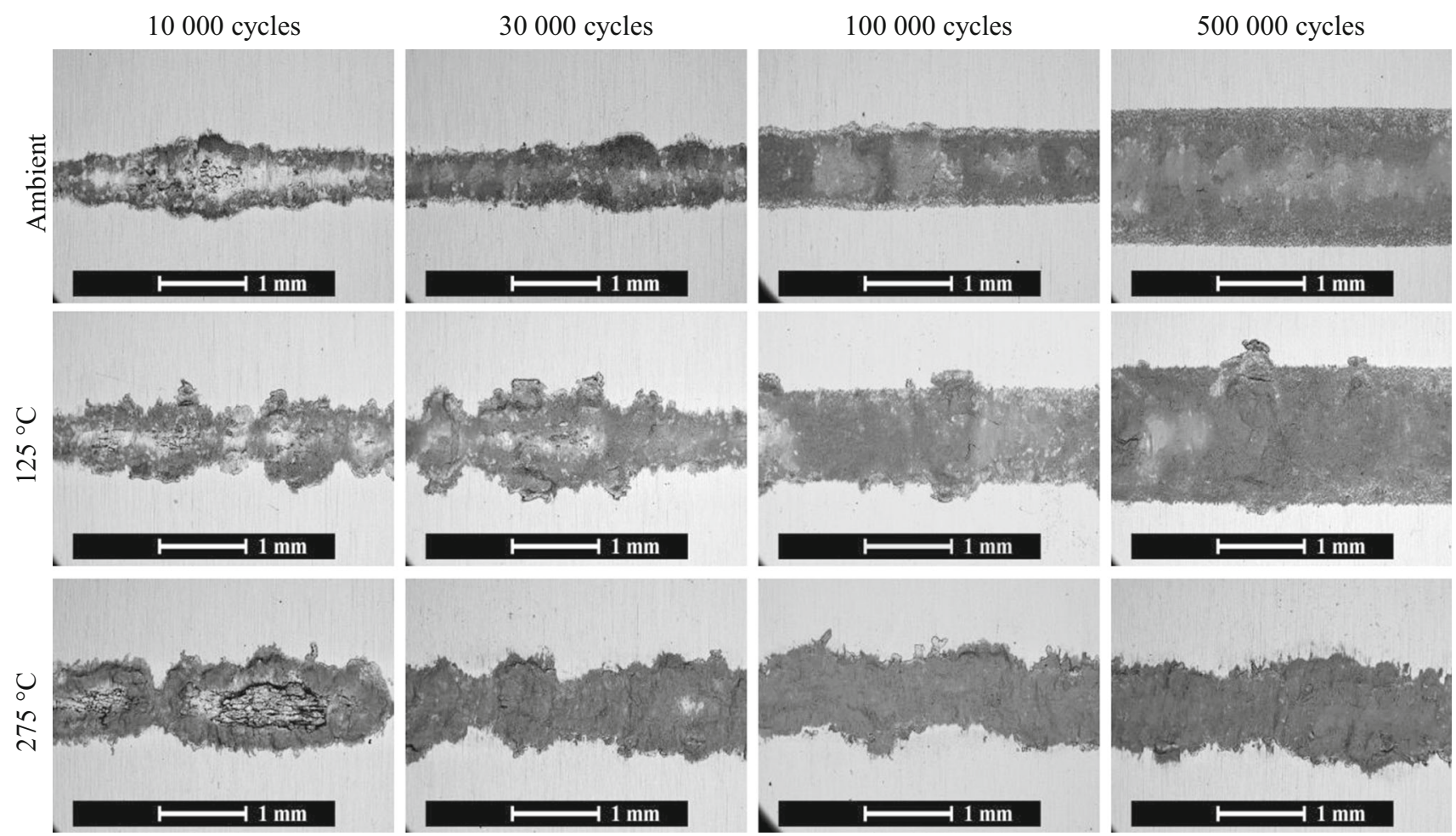

Fig. 13 Back-scattered electron SEM plan-view micrographs of wear scars on the flat specimens as a function of temperature and number of cycles at fretting frequency of $200 \mathrm{~Hz}$ 
To study the structure of oxide layers on the wear scars, the flat specimens from the tests fretted at $200 \mathrm{~Hz}$ for 100,000 cycles have been sectioned and examined via BSE SEM imaging in the same way as for the tests conducted at $20 \mathrm{~Hz}$. BSE SEM images of the cross sections are presented in Fig. 14. At room temperature, an oxide layer is observed on the two sides of the wear scar which is more compacted than the oxide layer of observed following fretting at the same test temperature under $20 \mathrm{~Hz}$; furthermore, EDX analysis indicates a higher oxygen content in the debris layer in the sample fretting at the higher frequency. Following fretting at $125{ }^{\circ} \mathrm{C}$, the debris layer is very different to that observed following fretting at the same temperature at $20 \mathrm{~Hz}$; at $200 \mathrm{~Hz}$, the debris layer is thin (about $5 \mu \mathrm{m}$ ) at the sides and no oxide layer is formed at the centre; moreover, there is no evidence of metallic particles being incorporated into the debris layer structure. However, as the temperature is increased further to $275{ }^{\circ} \mathrm{C}$, the differences between the oxide-based debris layers at the two fretting frequencies diminish; at $275^{\circ} \mathrm{C}$, the debris layer is again thin and highly compacted.
For all the wear scars shown in Fig. 14 generated following fretting at $200 \mathrm{~Hz}$, cracking in the bulk material was observed below the scar. Moreover, the degree and severity of the cracking observed increase with increasing test temperature. No such cracking was observed in any of the tests following fretting at $20 \mathrm{~Hz}$ (see Figs. 11, 12).

\section{Discussion}

It is clear that both test temperature and fretting frequency exert strong influences on the wear behaviour for the system examined. Their variation will cause changes in the underlying physical processes which together govern the overall fretting wear behaviour (i.e. the surface damage). These changes in the physical processes can either promote surface damage or protect the worn surface from further damage. An interaction diagram (Fig. 15) has been developed to describe the main physical processes which directly influence the wear behaviour and to relate these to changes in the parameters which were controlled in the text matrix, namely
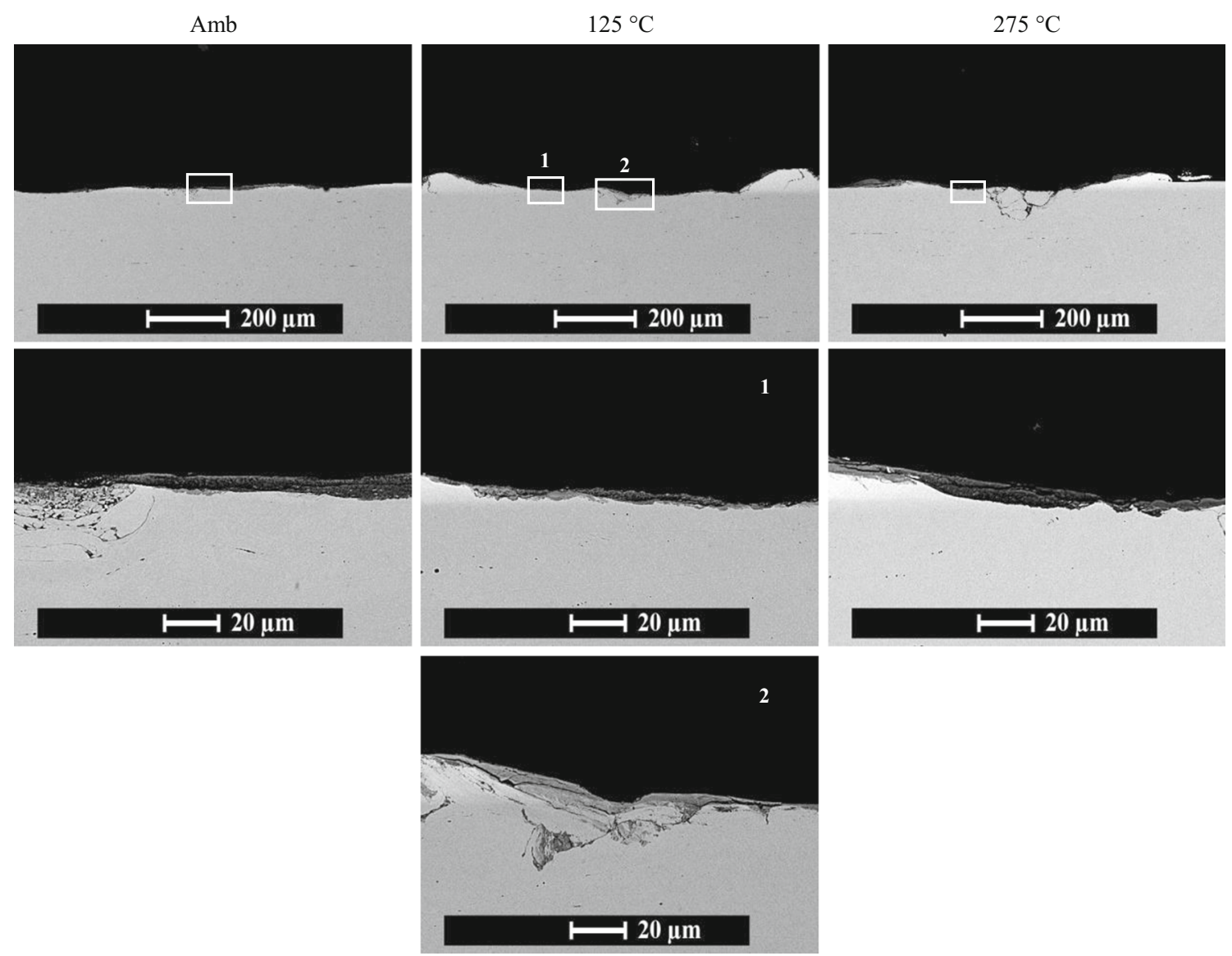

Fig. 14 Back-scattered electron SEM cross-sectional micrographs of wear scars on the flat specimens with different temperatures $\left(\right.$ Amb, $125^{\circ} \mathrm{C}$, $275^{\circ} \mathrm{C}$ ) at 100,000 cycles with fretting frequency of $200 \mathrm{~Hz}$ 


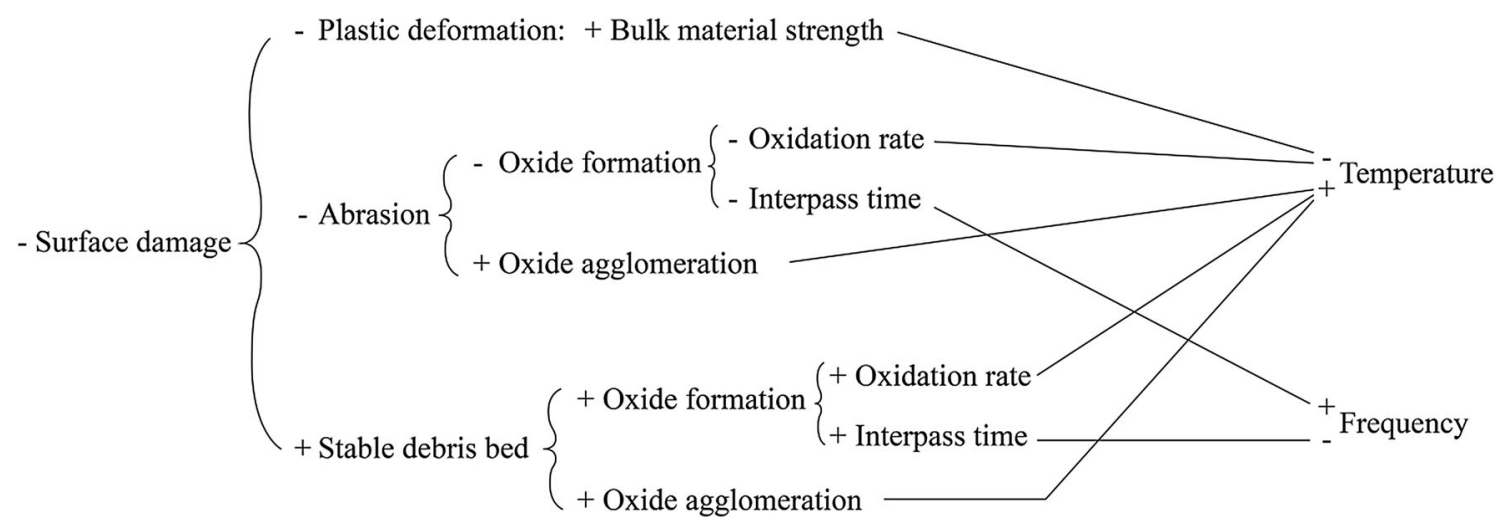

Fig. 15 Interaction diagram, linking the experimental parameters with the main features which influence the wear behaviour in terms of surface damage

temperature and frequency. Specifically, the diagram indicates how a change in the two controlled parameters (either a positive or negative change) will influence the basic physical processes (either positively or negatively) and thus how the damage will be influenced. For example, an increase in temperature will result in an increase in the oxidation rate and thus an increase in the amount of oxide formed. The influence of this on damage is less clear:

- The oxide may act in an abrasive manner and thus the increase in the amount of oxide formed would lead to an increased wear (note that on the interaction diagram (Fig. 15), this is described via a decrease in temperature);

- The higher temperature may also result in an increased tendency for oxide agglomeration which promotes formation of a stable oxide layer from the oxide debris which has formed; such a debris bed will protect the worn surface and lead to reduced wear.

In addition, the diagram (Fig. 15) indicates that a higher temperature will also result in a reduction in the bulk material strength which increases the plastic deformation and bulk material redistribution in the contact.

Similarly, an increase in fretting frequency can increase the temperature in the contact due to higher frictional power dissipation. However, an increase in fretting frequency will also result in a reduction in the inter-pass time (time between asperity interactions for a given asperity) which will reduce the oxide formation per cycle. This may reduce abrasion, but may also inhibit the formation of the debris bed at the same time. As such, the physical processes linked to changes in temperature and fretting frequency clearly compete against each other, and thus the change in the damage mechanism (and wear rate) will depend upon which of the influences is dominant.

The SEM images from the top of the wear scar on the flat specimens for the low frequency tests in Fig. 9 show that at room temperature, the wear scar keeps increasing in size as fretting proceeds, with no significant change in appearance (indicating no change in mechanism); this is in accord with the constant wear rate as observed in Fig. 6 . Clear metallic features are observed in all the wear scars, even with the highest numbers of fretting cycles, suggesting that the oxide debris bed is continually broken down and that a stable oxide layer to protect the wearing surface does not form. This continual formation and removal of the oxide layer in the fretting scar may explain the significant fluctuations (of about 0.1 ) in $\mu_{E}$ recorded throughout this test (Fig. 5a).

In contrast, the SEM images for the tests conducted at the highest temperature $\left(275^{\circ} \mathrm{C}\right)$ in Fig. 9 indicate that the wear scar developed to form a thick, protective debris bed in the first 10,000 cycles and thereafter did not significantly increase in width. The scar is covered with a complete, compacted oxide layer without any metallic features being observed. The $\mu_{\mathrm{E}}$ recorded in tests conducted at this test temperature dropped quickly and became low and stable after 20,000 cycles (see Fig. 5a). Together, these indicate that a stable oxide layer has formed and acted as a stable third body between the fretting surfaces; it has functioned as a solid lubricant and has protected the substrate material from further damage.

The comparison of the cross-sectional SEM images (Fig. 11) provides more details regarding the differences in the way that the oxide debris behaves at these two temperatures. The oxide debris formed at room temperature only covers part of the surface and appears to be loose and friable. At $275^{\circ} \mathrm{C}$, the oxide layer formed is thin but much more compacted. The higher temperature results in higher inter-particle force between individual the oxide debris particles [18], which encourages the retention of the debris inside the contact; additionally, the high temperature results in sintering which further enhances stability of the debris bed. In addition, EDX analysis indicates a higher 
oxygen level in the debris layer formed at the higher temperature.

At the critical temperature $\left(125^{\circ} \mathrm{C}\right)$ at $20 \mathrm{~Hz}$, the wear scar developed quickly in the first 100,000 cycles, but then became stable, and grew very little with further increases in the number of fretting cycles. The plan-view SEM images (Fig. 9) of scars generated at this temperature indicate that damage occurs in specific patches in the initial stages (unlike the pattern of damage seen in any other tests). The damage gradually fills in all along the scar as the number of fretting cycles increases. Very clear metallic features are observed in the wear scar in the early stages of fretting; however, the scar becomes almost completely covered with oxides in the later stages. A cross section through the wear scar after 100,000 cycles (Fig. 11) indicates that only a thin oxide debris existed at the centre of the scar; it is suggested that this is not a protective debris layer. In contrast, at the sides of the scar, a thick (about $20 \mu \mathrm{m}$ ) oxide layer exists. Following 500,000 cycles, the nature of the debris in the centre of the wear scar has changed; a relatively thick oxide layer has formed and covered much of the scar (Fig. 12). The very significant reduction in wear rate following 100,000 cycles (see Fig. 6) indicates that this oxide layer must be protective in nature; in contrast to the oxide layer formed at the highest temperature, this layer is thick (about $20 \mu \mathrm{m}$ ) and is less compacted. A change in wear behaviour has clearly occurred under this fretting condition. The oxidation rate at $125{ }^{\circ} \mathrm{C}$ will be higher than at room temperature [30]. However, the formation of the stable oxide layer takes longer than at $275^{\circ} \mathrm{C}$ as the temperature is not high enough to rapidly sinter the debris particles into a dense bed.

It is notable that at 100,000 cycles, the net wear volume $\left(V^{-}-V^{+}\right)$at the critical temperature is very similar to that observed at room temperature (see Fig. 7a). This indicates that the very deep scar observed at $125^{\circ} \mathrm{C}$ is associated with material redistribution. As indicated in Fig. 16, there is a significant reduction in the strength of 304 stainless steel between room temperature and $300{ }^{\circ} \mathrm{C}$ (the yield strength drops from almost $300 \mathrm{MPa}$ to $<150 \mathrm{MPa}$ over this range). It should also be noted that the redistribution of material starts to occur only at some positions along the contact and gradually covers the whole wear scar as the number of fretting cycles increases (see Figs. 9, 10). This indicates that the formation and breakdown of the thick oxide layer (observed in Figs. 11, 12) at the critical temperature may cause the actual contact between the fretting specimens to be concentrated in just a few places; this can result in very high contact pressures at those positions which go on to cause the very uneven damage across the contact line as observed in Fig. 10. The contact pressure concentration together with the reduction in strength at

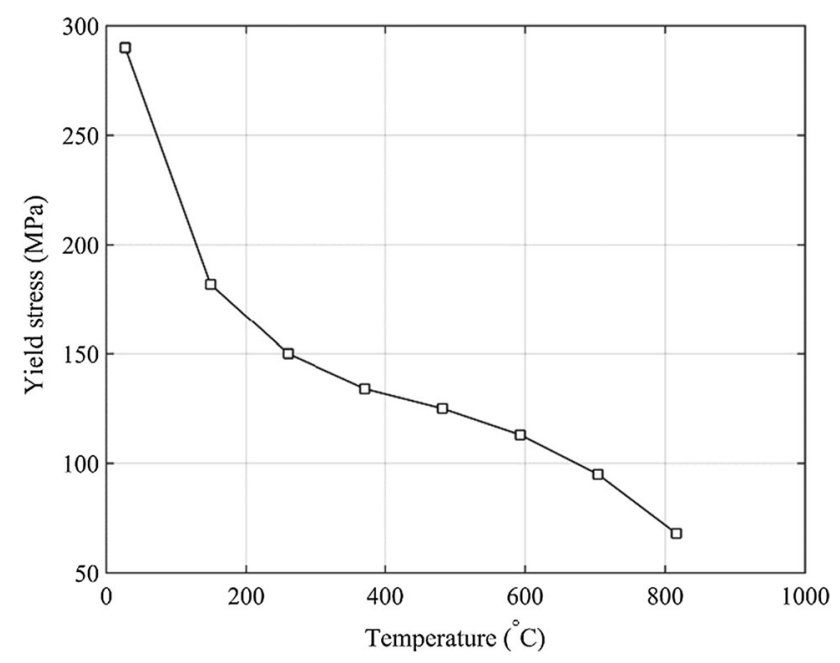

Fig. 16 Yield strength of 304 stainless steel as a function of temperature [6]

$125{ }^{\circ} \mathrm{C}$ results in a much higher degree of plastic deformation of the bulk material due to the tractional forces in fretting. The bulk material at the centre is therefore pushed to the sides and forms the significant build-up of material at the edges of the scar (see Figs. 8, 11). When the temperature is further increased to $275{ }^{\circ} \mathrm{C}$, the formation of the stable debris bed results in (1) a reduction in the tractional force (see Fig. 11) due to a reduction in the coefficient of friction and (2) uniform contact surfaces without highpressure concentration; in addition, the wear scar becomes much shallower, thus reducing the tractional forces associated with the ploughing effect [31]. Despite the yield stress of the substrate itself reducing further at this increased temperature, the dense debris later formed is clearly able to shield the substrate material since no gross plastic deformation is observed.

The plan-view SEM images for the high frequency $(200 \mathrm{~Hz})$ fretting tests (Fig. 13) show that at all three temperatures examined, significant portions of the metal surface are exposed (without any covering of oxide-based debris) in the early stages of scar development. This indicates that less oxide is formed within the same numbers of fretting cycles because of the reduction in inter-pass time. This reduction in the rate of oxide formation may result in a reduction in the rate of abrasion, and also a reduction in the rate of material being lost from the contact in the form of oxide, both of which will contribute to the reduction in wear rate compared to that observed at the lower fretting frequency (Fig. 6). In the tests conducted at $125^{\circ} \mathrm{C}$ and $200 \mathrm{~Hz}$, no discontinuity in the development of the wear volume with number of cycles was observed (Fig. 6); the wear volume increases almost linearly with the number of cycles with the rate being almost the same as the rate observed at the room temperature. This indicates that no 
fully protective oxide layer has been formed by 500,000 cycles. Figure 13 shows that at $125^{\circ} \mathrm{C}$, the scar surface which is evident following 500,000 cycles still has significant metallic character, which indicates that the oxide is being lost and reformed within the contact. Its inability to build a protective debris bed results from the shorter interpass time; this is despite the increase in contact temperature that will result from the higher frictional power dissipation at this frequency (estimated to be of the order of 70-150 K by Jin et al. [5]), and indicates that the effect of the reduced inter-pass time dominates over that of the increased temperature. In addition, material build-up only appears at some positions along the wear scar, and it is much less significant compared to that observed in the low frequency test (see Fig. 14). At the highest temperature examined $\left(275^{\circ} \mathrm{C}\right)$, the oxidation rate is high enough that (despite the shorter inter-pass times at this high fretting frequency) a stable oxide debris bed has been able to form, which has resulted in the associated low rates of wear being observed.

Cracks are observed both in the cross-sectional (Fig. 14) SEM images for the high frequency tests. This implies that fretting fatigue dominated the damage at some stage of the fretting process. Because of the lower oxidation rate of the high frequency test at the early stage, more direct metal to metal contacts are expected at the first few thousands cycles. This can lead to more material adhesion and less gross sliding wear, which may result in the cracks observed. Furthermore, the increase in fretting frequency would cause significant reduction in fretting fatigue life [32], which makes cracks more likely to occur under high fretting frequency, even at the same number of cycles. The cracks get longer and the damage areas increase with increasing temperature. The reduction in strength of the bulk material as shown in Fig. 16 is the underlying feature which governs this behaviour.

\section{Conclusions}

The mechanisms and rates of fretting wear for 304 stainless steel were found to be significantly influenced by both environmental temperature and fretting frequency. At low temperatures, fretting was associated with the formation of oxide debris which was continually expelled from the contact as wear proceeded. As the temperature was increased, the mechanisms changed such that the oxide which was formed was retained in the contact and developed into a protective oxide bed which resulted in very much reduced rates of wear. The temperature at which this transition takes place is dependent upon the fretting frequency. The influence of these two parameters (temperature and fretting frequency) on the mechanisms and rates of fretting are complex and interdependent, relating to rates of formation of oxide, the tendency for the oxide formed to be either retained in or rejected from the contact, and the changes in the strength and fatigue behaviour of the materials. Many influences compete, but those which influence the tendency of the oxide to be retained in the contact and form a protective debris bed are found to be dominant.

Acknowledgements The authors wish to thank the Taiho Kogyo Tribology Research Foundation, Toyota City, Japan, for supporting an upgrade of the experimental facilities which have underpinned this work. The views expressed in this paper are those of the authors and not necessarily those of the Taiho Kogyo Tribology Research Foundation. The authors would also like to thank the University of Nottingham for the award of the "Dean of Engineering Research Scholarship for International Excellence" to Xiaozhe Jin.

Open Access This article is distributed under the terms of the Creative Commons Attribution 4.0 International License (http://crea tivecommons.org/licenses/by/4.0/), which permits unrestricted use, distribution, and reproduction in any medium, provided you give appropriate credit to the original author(s) and the source, provide a link to the Creative Commons license, and indicate if changes were made.

\section{References}

1. Vingsbo, O., Söderberg, S.: On fretting maps. Wear 126, 131-147 (1988). doi:10.1016/0043-1648(88)90134-2

2. Jin, X., Shipway, P.H., Sun, W.: The role of frictional power dissipation (as a function of frequency) and test temperature on contact temperature and the subsequent wear behaviour in a stainless steel contact in fretting. Wear 330-331, 103-111 (2015). doi:10.1016/j.wear.2015.02.022

3. Hirsch, M.R., Neu, R.W.: Influence of temperature on the fretting response between AISI 301 stainless steel and AISI 52100 steel. Tribol. Int. 68, 77-84 (2013). doi:10.1016/j.triboint.2012.11.004

4. Hirsch, M.R., Neu, R.W.: Temperature-dependent fretting damage of high strength stainless steel sheets. Wear 346, 6-14 (2016). doi:10.1016/j.wear.2015.10.007

5. Jin, X., Sun, W., Shipway, P.H.: The role of geometry changes and debris formation associated with wear on the temperature field in fretting contacts. Tribol. Int. 102, 392-406 (2016). doi:10. 1016/j.triboint.2016.05.043

6. Nikulin, I., Kaibyshev, R., Skorobogatykh, V.: High temperature properties of an austenitic stainless steel. J. Phys: Conf. Ser. 240, 012071 (2010). doi:10.1088/1742-6596/240/1/012071

7. Kapoor, A.: Wear by plastic ratchetting. Wear 212, 119-130 (1997). doi:10.1016/S0043-1648(97)00083-5

8. Fouvry, S., Kapsa, P., Vincent, L.: An elastic-plastic shakedown analysis of fretting wear. Wear 247, 41-54 (2001). doi:10.1016/ S0043-1648(00)00508-1

9. Hurricks, P.L.: The mechanism of fretting-a review. Wear 15, 389-409 (1970). doi:10.1016/0043-1648(70)90235-8

10. Godet, M.: The third-body approach: a mechanical view of wear. Wear 100, 437-452 (1984). doi:10.1016/0043-1648(84)90025-5

11. Berthier, Y., Vincent, L., Godet, M.: Velocity accommodation in fretting. Wear 125, 25-38 (1988). doi:10.1016/00431648(88)90191-3

12. Colombie, C., Berthier, Y., Floquet, A., Vincent, L., Godet, M.: Fretting: load carrying capacity of wear debris. J. Tribol. Trans. ASME. 106, 194-201 (1984). doi:10.1115/1.3260881 
13. Kato, H., Komai, K.: Tribofilm formation and mild wear by tribosintering of nanometer-sized oxide particles on rubbing steel surfaces. Wear 262, 36-41 (2007). doi:10.1016/j.wear.2006.03. 046

14. Iwabuchi, A., Hori, K., Kubosawa, H.: The effect of oxide particles supplied at the interface before sliding on the severe-mild wear transition. Wear 128, 123-137 (1988). doi:10.1016/00431648(88)90179-2

15. Hurricks, P.L.: The fretting wear of mild steel from room temperature to $200{ }^{\circ} \mathrm{C}$. Wear 19, 207-229 (1972). doi:10.1016/00431648(72)90304-3

16. Hurricks, P.L.: The fretting wear of mild steel from 200 to $500{ }^{\circ} \mathrm{C}$. Wear 30, 189-212 (1974). doi:10.1016/00431648(74)90175-6

17. Kayaba, T., Iwabuchi, A.: The fretting wear of $0.45 \% \mathrm{C}$ steel and austenitic stainless steel from 20 to $650{ }^{\circ} \mathrm{C}$ in air. Wear 74, 229-245 (1981). doi:10.1016/0043-1648(81)90165-4

18. Jiang, J., Stott, F.H., Stack, M.M.: The role of triboparticulates in dry sliding wear. Tribol. Int. 31, 245-256 (1998). doi:10.1016/ S0301-679X(98)00027-9

19. Clark, W.T., Pritchard, C., Midgley, J.W.: Paper 12: mild wear of unlubricated hard steels in air and carbon dioxide. Proc. Inst. Mech. Eng. Conf. Proc. 182, 97-106 (1967). doi:10.1243/pime_ conf_1967_182_411_02

20. Foley, R.T., Peterson, M.B., Zapf, C.: Frictional characteristics of cobalt, nickel, and iron as influenced by their surface oxide films. ASLE Trans. 6, 29-39 (1963). doi:10.1080/05698196308971996

21. Stott, F.H., Wood, G.C.: The influence of oxides on the friction and wear of alloys. Tribol. Int. 11, 211-218 (1978). doi:10.1016/ 0301-679X(78)90178-0

22. Stott, F.H.: High-temperature sliding wear of metals. Tribol. Int. 35, 489-495 (2002). doi:10.1016/S0301-679X(02)00041-5

23. German, R.M.: Sintering Theory and Practice. Wiley, Hoboken (1996)
24. Pearson, S.R., Shipway, P.H., Abere, J.O., Hewitt, R.A.A.: The effect of temperature on wear and friction of a high strength steel in fretting. Wear 303, 622-631 (2013). doi:10.1016/j.wear.2013. 03.048

25. Attia, M.H., D’Silva, N.S.: Effect of mode of motion and process parameters on the prediction of temperature rise in fretting wear. Wear 106, 203-224 (1985). doi:10.1016/0043-1648(85)90110-3

26. Warmuth, A.R., Shipway, P.H., Sun, W.: Fretting wear mapping: the influence of contact geometry and frequency on debris formation and ejection for a steel-on-steel pair, Proc. R. Soc. Lond. A Math. Phys. Eng. Sci. (2015). doi:10.1098/rspa.2014.0291

27. Fouvry, S., Kapsa, P., Zahouani, H., Vincent, L.: Wear analysis in fretting of hard coatings through a dissipated energy concept. Wear 203-204, 393-403 (1997). doi:10.1016/S00431648(96)07436-4

28. Pearson, S.R., Shipway, P.H.: Is the wear coefficient dependent upon slip amplitude in fretting? Vingsbo and Söderberg revisited. Wear 330-331, 93-102 (2014). doi:10.1016/j.wear.2014.11.005

29. Everitt, N.M., Ding, J., Bandak, G., Shipway, P.H., Leen, S.B., Williams, E.J.: Characterisation of fretting-induced wear debris for Ti-6Al-4V. Wear 267, 283-291 (2009). doi:10.1016/j.wear. 2008.12.032

30. Ashby, M.F., Jones, D.R.H.: Engineering Materials 1: An Introduction to Properties, Applications and Design, pp. 210-236. Elsevier Science, Oxford (2005)

31. Fouvry, S., Duó, P., Perruchaut, P.: A quantitative approach of Ti-6Al-4 V fretting damage: friction, wear and crack nucleation. Wear 257, 916-929 (2004). doi:10.1016/j.wear.2004.05.011

32. Iyer, K., Mall, S.: Effects of cyclic frequency and contact pressure on fretting fatigue under two-level block loading. Fatigue Fract. Eng. Mater. Struct. 23, 335-346 (2000). doi:10.1046/j. 1460-2695.2000.00288.x 